\title{
MODEL PENERIMAAN TEKNOLOGI BELAJAR MEMBACA ANAK USIA DINI BERDASARKAN KONSEP TAM
}

\author{
Dwi Marlina \\ Program Studi Informatika, Universitas Indraprasta PGRI \\ E-Mail: dhuwie.marlina@gmail.com
}

\begin{abstract}
Abstrak
Transportasi pengajaran dengan menggunakan teknologi dapat membantu tugas pendidik dan membantu menumbuhkan minat belajar pada anak didik. Penelitian ini dilakukan untuk mengetahui faktor-faktor yang mempengaruhi diterima dengan baik atau tidaknya Software Belajar Membaca Interaktif Anak Usia Dini bagi penggunanya dan juga untuk mengetahui hubungan kausal antara faktor-faktor yang mempengaruhi penerimaan software tersebut. Model yang digunakan untuk mengetahui penerimaan software Pembelajaran Cara Membaca untuk Anak Usia Dini ini adalah model TAM (Technology Acceptance Model). Secara terinci model TAM menjelaskan penerimaan teknologi informasi dengan dimensi-dimensi tertentu yang dapat mempengaruhi penerimaan teknologi oleh pengguna. Model ini menempatkan faktor sikap dan tiap-tiap perilaku pengguna dengan menggunakan dua variabel utama yaitu kemanfaatan (usefulness) dan kemudahan penggunaan (easy of use). Model penerimaan software Belajar Membaca Untuk Anak usia Dini ini juga dipengaruhi oleh faktor lain antara lain: Computer Self Efficacy (CSE) atau kemampuan diri pada komputer, Perceived Ease of USe (PEOU)) atau persepsi kemudahan penggunaan, Perceived Usefulness (PU) atau persepsi kemanfaatan, Attitude Toward Using (ATU) atau sikap terhadap penggunaan, Behavior Intention To Use (BITU) atau niat tingkah laku untuk menggunakan dan Actual System Usage (ASU) atau kondisi nyata penggunaan sistem. Uji statistik dilakukan dengan menggunakan Structural Equation Modeling (SEM) yang diolah melalui software AMOS versi 7.0. Hasil Penelitian ini adalah diterimanya software membaca dengan baik pada anak usia Taman Kanak-kanak.
\end{abstract}

Kata kunci: Software Belajar Membaca Interaktif, Anak Usia Dini, dan TAM

\begin{abstract}
Transportation of education through the use of technology can support educators' task and stimulate interest in learning among students. This research is conducted to find out the factors that influence whether Interactive Learning to Read Software for Early Childhood is well received by its users or not and to determine the causal relationship among the factors that affecting the acceptance of such software. The model used to determine the acceptance of the software Learn How to Read for Early Childhood is TAM (Technology Acceptance Model). TAM explains in detail the model of information technology acceptance with a certain dimension that can affect technology acceptance by users. This model puts factors of attitude and behavior of each user by using two main variables, namely expediency (usefulness) and ease of use (easy to use). The model of acceptance of Learning to Read Software for Early Childhood software is also influenced by other factors such as: Computer Self Efficacy (CSE), Perception of Ease of Use (PEOU), Perception of Usefulness (PU), Attitude toward Using (ATU), Behavioral Intention To Use (BITU), and Actual System Use (ASU). Statistical test is performed using Structural Equations Modeling (SEM), which are processed by applying software AMOS version 7.0. The result of the research shows that the reading software is well accepted by kindergarten children.
\end{abstract}

Keywords: Interactive learning to read software, early childhood and TAM 


\section{Pendahuluan}

Perkembangan komputer yang begitu pesat sudah merambah dalam berbagai bidang kehidupan, tidak terkecuali bidang pendidikan. Sebagian besar anak-anak sejak usia dini, dalam semua aspek kehidupan, pendidikan dan hiburan telah menyatu erat dengan teknologi dan komputer. Transformasi pengajaran dengan menggunakan kemajuan teknologi pendidikan dapat membantu tugas pendidik sebagai tenaga pendidik dan membantu menumbuhkan minat belajar anak didik secara mandiri, serta membantu kreatifitas anak didik untuk belajar. Hal tersebut harus mulai dikenalkan sejak jenjang pendidikan prasekolah sehingga potensi kecerdasan anak dapat di gali sejak dini.

Kemampuan membaca adalah salah satu ketrampilan sangat penting yang dibutuhkan anakanak mengarungi dunia pembelajaran. Berbagai metode belajar membaca pun bermunculan untuk membantu para guru dan orang tua mengajarkan ketrampilan ini. Akan tetapi, metode saja sebetulnya tidak cukup, sebab setiap anak itu unik, dan keunikan itu membutuhkan layanan metode yang berbeda-beda. Bermain merupakan cara yang paling baik untuk mengembangkan kemampuan anak. Dengan pembelajaran bermain sambil belajar dengan komputer anak didik dapat belajar secara mandiri baik di rumah maupun di sekolah tentang materi pembelajaran seperti pengenalan huruf alphabet, angka, warna, nama buah, nama hewan, bentuk benda, pengenalan organ tubuh serta pengenalan alat transportasi tanpa harus menunggu untuk bertanya kepada pendidik saat mengalami kesulitan.

Komputer sebagai media pendidikan sudah merambah ke tingkat pendidikan prasekolah yaitu Taman Kanak-kanak. Di Taman Kanak-kanak sekarang ini sudah menggunakan komputer sebagai alat bantu/media di dalam pembelajaran dengan menggunakan softwaresoftware yang sesuai dengan perkembangan anak usia dini untuk membantu menumbuhkan minat belajar pada anak khususnya minat belajar membaca. Para pendidik di Taman Kanakkanak sangat terbantu dengan adanya media pembelajaran dengan komputer. Seiring dengan hal tersebut, tidak semua Taman Kanak-kanak menggunakan media pembelajaran dengan komputer, hanya beberapa sekolah saja yang sudah menggunakan dan tidak semua orang tua juga dapat menggunakan media tersebut. Untuk itulah penelitian ini mencoba untuk mengkaji sampai sejauh mana penerimaan teknologi pembelajaran khususnya cara membaca untuk anak usia dini dapat diterima di berbagai lembaga pendidikan anak usia dini khususnya di Kecamatan Jagakarsa.

Tujuan yang ingin dicapai dengan adanya penelitian ini adalah:

1. Untuk mengetahui tingkat penerimaan Software Belajar Membaca Interaktif di Taman Kanak-kanak.

2. Untuk mendeteksi faktor-faktor yang mempengaruhi tingkat penerimaan software Belajar Membaca Interaktif bagi penggunanya

3. Untuk menguji tingkat signifikasi hubungan kausal antara faktor-faktor yang mempengaruhi penerimaan software.

4. Untuk mendapatkan model penerimaan software yang tepat bagi anak usia dini khususnya di Taman Kanak-kanak wilayah Kecamatan Jagakarsa.

Penelitian ini diharapkan dapat membantu organisasi atau Taman Kanak-kanak untuk mengidentifikasi dan meningkatkan penerimaan teknologi melalui penggunaan Software Belajar Membaca Interaktif sebagai software aplikasi untuk membantu user atau pengguna mengenal huruf alfabet dan cepat dalam membaca yang menjadi permasalahan sosial dan permasalahan yang membutuhkan pengolahan data secara statistik dengan menggunakan variabel laten. 


\section{Hipotesis}

Hipotesis dalam penelitian ini adalah diduga teknologi pembelajaran cara baca usia dini di Kecamatan Jagakarsa dapat diterima penggunanya.

\section{Tinjauan Pustaka}

\section{Penerimaan Teknologi Informasi}

(Iqbaria, 1994) menyatakan bahwa, secara individu maupun kolekif penerimaan teknologi dapat dijelaskan dari variasi penggunaan suatu sistem, karena diyakini bahwa penggunaan suatu sistem yang berbasis TI dapat meningkatkan kinerja individu atau kinerja organisasi. Untuk mengetahui indikator penerimaan TI, secara umum diketahui bahwa penerimaan TI dapat dilihat dengan adanya indikator penggunaan sistem dan frekuensi penggunaan komputer, atau dari aspek kepuasan pengguna dan ada juga yang menjadikan penggunaan sistem sebagai indikator utama penerimaan teknologi oleh penggunanya.

\section{Theory Of Reasoned Action (TRA)}

Beberapa model yang dibangun untuk menganalisis dan memahami faktor-faktor yang mempengaruhi diterimanya penggunaan teknologi, yang tercatat dalam berbagai literatur dan referensi hasil penelitian di bidang Teknologi Informasi, diantaranya Theory of Reasoned Action (TRA). Teori alasan bertindak (Theory of Reasoned Action atau TRA) merupakan teori perilaku manusia yang paling mendasar dan berpengaruh (Fishbein dan Ajzen, (1980) dalam Widodo, 2006c,) Teori ini diturunkan dari penelitian-penelitian sebelumnya yang dimulai dari teori sikap (Theory of Attitude) yang mempelajari tentang sikap (attitude) dan perilaku (behavior). Teori ini disusun menggunakan asumsi dasar bahwa manusia berperilaku dengan cara yang sadar dan mempertimbangkan segala informasi yang tersedia. Dalam TRA, niat seseorang untuk melakukan suatu perilaku menentukan akan dilakukan atau tidak dilakukannya perilaku tersebut. Niat melakukan atau melakukan adalah sikap (attitude toward behavior) dan pengaruh sosial yaitu norma subjektif (subjective norms). Dalam upaya mengungkapkan pengaruh sikap dan norma subjektif terhadap niat untuk dilakukannya atau tidak dilakukannya perilaku ini dengan kenyakinan (beliefs). Dengan itu, sikap berasal dari kenyakinan terhadap perilaku (behavioral beliefs), sedangkan norma sukjektif berasal dari kenyakinan normative (normative beliefs).

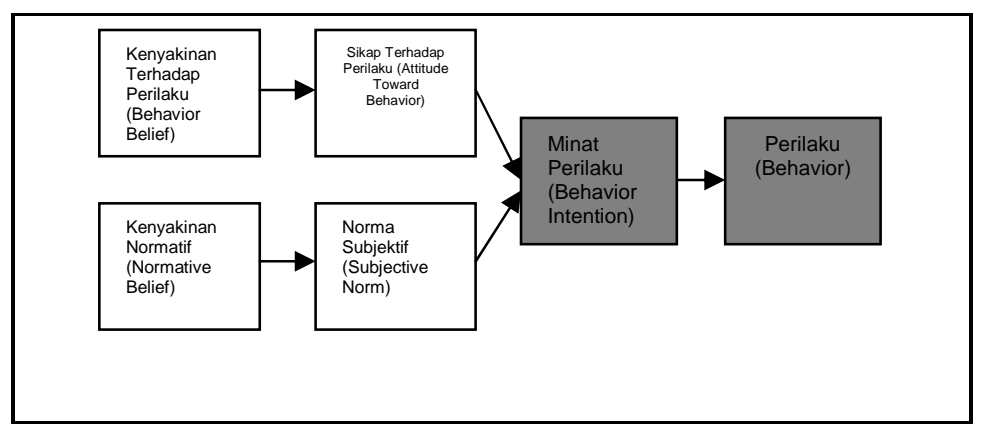

Gambar 1. Theory of Reasoned Action

Sumber : (Fishbein dan Ajzen, 1980:54)

\section{Aspek Perilaku (behavior) dalam Penerimaan Teknologi Informasi.}

Menurut (Syam, 1999), penggunaan Teknologi Informasi (TI) bagi perusahaan ditentukan oleh banyaknya faktor, salah satunya adalah karakteristik pengguna TI. Perbedaan karakteristik pengguna TI juga dipengaruhi oleh aspek persepsi, sikap dan perilaku dalam menerima penggunaan TI. Pengguna suatu sistem adalah manusia yang secara psikologis 
memiliki perilaku (behavior) tertentu yang telah ada pada dirinya, yang menyebabkan aspek perilaku dalam pengguna suatu teknologi informasi menjadi faktor yang penting pada setiap orang yang menggunakan teknologi informasi.

Penggunaan teknologi informasi, pemanfaatan informasi oleh individual, kelompok maupun organisasi merupakan variabel inti dalam riset sistem informasi, sebab sebelum digunakan terlebih dahulu dipastikan tentang penerimaan atau penolakan digunakannya TI tersebut, hal ini berkaitan dengan perilaku yang ada individu/organisasi yang menggunakan teknologi komputer. Pendapat tersebut oleh Sri Astuti pada tahun 2001 sejalan dengan penelitian yang dilakukan oleh Guimares dan Ramanujan pada tahun 1996, menemukan bahwa penerapan TI dalam suatu organisasi mendorong terjadinya perubahan revolusioner terhadap perilaku individu dalam bekerja, dan dalam konteks penggunaan PC, kemungkinan seseorang mempunyai keyakinan bahwa penggunaan komputer akan memberikan manfaat bagi dirinya dan pekerjaannya (Indriantoro Nur , 2000).

\section{Technology Acceptance Model (TAM)}

Model TAM menjelaskan perilaku pengguna komputer, yaitu berlandaskan pada kepercayaan (beliefs), sikap (attitude), niat (intention), dan hubungan perilaku pengguna (user behavior relationship). Tujuan model ini untuk menjelaskan faktor-faktor utama dari perilaku penggunaan TI. Model TAM secara lebih terperinci menjelaskan penerimaan TI dengan dimensi-dimensi tertentu yang dapat mempengaruhi dengan mudah diterimanya TI oleh pengguna. Model TAM menempatkan faktor sikap dari tiap-tiap perilaku pengguna dengan dua variabel yaitu kemanfaatan (usefulness) dan kemudahan penggunaan (ease of use). Kedua variabel tersebut dapat menjelaskan aspek keprilakuan pengguna (Davis, 1989).

\section{Structural Equation Modeling (SEM)}

Structural Equation Modeling (SEM) merupakan suatu teknik statistik yang mampu menganalisis variabel laten, variabel indikator dan kesalahan pengukuran secara langsung. Dengan mengggunakan Structural Equation Modeling (SEM), memungkinkan untuk dapat menganalisis hubungan antara variabel laten yang satu dengan variabel indikatornya, hubungan antara variabel laten yang satu dengan variabel laten yang lainnya, juga dapat diketahui besarnya kesalahan pengukuran. Selain dapat menganalisis hubungan dua arah yang sering kali muncul dalam ilmu sosial dan perilaku.

Hair (1998:406) mengajukan tahapan pemodelan dan analisis persamaan struktural menjadi 7 (tujuh) langkah yaitu:

Tabel 1. Langkah-langkah SEM

\begin{tabular}{cl}
\hline Langkah & \multicolumn{1}{c}{ Operasional } \\
\hline 1 & Pengembangan sebuah model berbasis teori \\
2 & $\begin{array}{l}\text { Menyusun diagram jalur untuk menyatakan hubungan kausalitas } \\
\text { Menterjemahkan diagram jalur ke dalam persamaan-persamaan struktural dan } \\
\text { spesifikasi model pengukuran }\end{array}$ \\
4 & Memilih matrik input dan model/teknik estimasi \\
5 & Menilai problem identifikasi \\
6 & Evaluasi Estimasi Model \\
7 & Interprestasi dan Modifikasi Model \\
\hline
\end{tabular}

Fasilitas Media Sebagai Alat Bantu Pembelajaran Membaca Pada Anak

Kemajuan media komputer memberikan beberapa kelebihan untuk kegiatan produksi audio visual. Pada tahun-tahun belakangan komputer mendapat perhatian besar karena kemampuannya yang dapat digunakan dalam bidang kegiatan pembelajaran. Pembelajaran 
yang dibantu komputer dikenal dengan nama CAI yaitu "Computer Assited Instruction". Prinsip pembelajaran ini menggunakan komputer sebagai alat bantu menyampaikan pelajaran kepada user secara interaktif. Perubahan metode pembelajaran dan pengajaran telah menyebabkan alat yang digunakan menjadi meluas, misalnya: video, audio, slide dan film.

\section{Software Belajar Membaca Interaktif}

Software Belajar Membaca Interaktif adalah suatu cara agar anak bisa cepat dan mudah belajar membaca melalui berbagai latihan dan permainan (games). Dengan sentuhan IT, menggunakan multimedia, anak dapat belajar membaca secara interaktif menggunakan media komputer, sehingga anak dapat belajar secara bebas, berulang-ulang tanpa adanya batasan waktu. Anak dapat belajar kapan saja baik dengan arahan guru, orangtua maupun mandiri. Program ini telah memadukan tulisan, suara, gambar secara animasi dan melalui permainan (games). Dengan harapan bisa menarik anak dan tidak cepat bosan. Dengan cara ini anak bisa belajar dan juga bermain.

Software belajar interaktif produksi oleh eMedio (Studio Media Edukasi). Wedsite : http://softwarebelajar.blogspot.com. Email:emedio@gmail.com

\section{Metodologi Penelitian}

\section{Jenis Penelitian}

Penelitian ini merupakan penelitian eksplanatori mengenai hubungan kausal (sebab akibat) dari variabel-varibel yang diamati dan diteliti. Penelitian yang dilakukan bermaksud membuktikan hipotesa yang dibangun dengan pendekatan Technologi Acceptance Model (TAM), diuji menggunakan perangkat lunak Amos 7.0. Dengan metode ini akan dilakukan analisis terhadap faktor-faktor yang mempengaruhi penerimaan software Belajar Membaca Interaktif. Teknik pengumpulan data dilakukan dengan kuesioner terhadap guru dan orang tua Taman Kanak-kanak di wilayah Kecamatan Jagakarsa. Kuesioner diberikan kepada guru dan orang tua secara langsung.

\section{Metode Pemilihan Sampel}

Populasi dari penelitian ini adalah guru dan orang tua murid Taman Kanak-kanak di Wilayah Kecamatan Jagakarsa sejumlah 200. Penentuan jumlah sampel berdasarkan syarat jumlah sampel minimal untuk SEM, yaitu 100-200 (Hair et. At., 1998) dengan menggunakan perbandingan jumlah sampel terhadap jumlah indikator. Metode yng digunakan untuk mendapatkan data empiris melalui kuesioner berskala semantic diferensial. Semantic diferensial digunakan untuk mengukur sikap tidak dalam bentuk pilihan ganda atau checklist, tetapi tersusun dari sebuah garis kontinu, nilai negatif terletak di sebelah kiri dan nilai positif terletak di sebelah kanan.

\section{Metode Pengumpulan Data \\ Studi Pustaka}

Studi Pustaka merupakan pengumpulan data skunder. Studi Pustaka dilakukan untuk mencari dan mendapatkan data-data yang bersifat teoritis dan berhubungan dengan penelitian yang sedang dilakukan. Dengan mempelajari literatur-literatur, jurnal-jurnal penelitian, bahan kuliah dan sumber-sumber lainnya dari internet yang berhubungan dengan penelitian.

\section{Kuesioner}

Kuesioner merupakan pengumpulan data primer. Untuk mendapatkan data-data yang dibutuhkan, pengumpulan data dilakukan melalui kuesioner bersifat closed question yang berupa pertanyaan-pertanyaan yang dibuat untuk mengetahui bagaimana pengaruh antara 
variabel persepsi kamampuan diri terhadap komputer (Computer Self Efficacy/CSE), persepsi kemudahan menggunakan (Perceived Ease of Use/PEOU), persepsi kemanfaatan (Perceived Usefulness/PU), sikap pengguna (Attitude Toward Using/ATU), perilaku pengguna (Behavioral Intention to Use/BITU) dan perilaku nyata (Actual System Usage/ASU).

\section{Instrumen Penelitian}

Penelitian ini menggunakan instrument kuesioner yang dibuat dengan menggunakan closed questions. Dengan menggunakan closed question, responden dapat dengan mudah menjawab kuesioner dan data dari kuesioner itu dapat dengan cepat dianalisis secara statistik, serta pernyataan yang sama dapat diulang dengan mudah. Kuesioner yang dibuat dengan menggunakan skala interval atau Semantic Differential.

\section{a. Teknik Analisa Data}

\section{Analisa Statistik Deskriptif}

Teknik Analisis Data menggunakan Analisis statistik deskriptif. Analisis statistik deskriptif dilakukan untuk menelaah distribusi frekuensi ukuran pemusatan, dan penyebaran data tentang karateristik sampel (responden) dan indikator-indikator variabel Computer Self Efficacy (CSE), Perceived Ease of Use (PEOU), Perceived Usefulness (PU) Attitude Toward Using (ATU), Behavioral Intention To Use (BITU), dan Actual System Usage (ASU). Ukuran pemusatan yang ditelaah meliputi mean, median dan modus. Sedangkan ukuran penyebaran yang ditelaah meliputi maksimum, minimum, standar deviasi, dan varian.

\section{Analisa Statistik Inferensial}

Pengujian hipotesis yang dilakukakan peneliti dengan menggukanan metode statistik multivariat dependensi Structural Equation Model (SEM). Tujuan utama analisis statistik inferensial dengan menggunakan SEM adalah untuk memperoleh model yang plausible atau fit (sesuai, cocok) bagi permasalahan yang sedang dikaji dalam kausal antar variable dependen dan independen pada model yang dibangun pada penelitian ini.

Tahapan pemodelan dan analisis persamaan structural menjadi 7 (tujuh) langkah yaitu: pengembangan berbasis model,membangun diagram jalur (diagram path), konversi diagram jalur ke persamaan structural, memilih matriks input dan estimasi model, evaluasi masalah identifikasi model, evaluasi asumsi dan kesesuaian model, dan Interpretasi dan modifikasi model.

\section{Hasil dan Pembahasan}

\section{Analisis Statistik Deskriptif}

Pengukuran deskriptif pada dasarnya memaparkan secara numerik ukuran tendensi sentral, dispersi dan distribusi suatu data. Tendensi sentral mengukur pemusatan data. Ada beberapa ukuran umum tendensi sentral yang digunakan, yaitu: Mean (rata-rata), median (nilai tengah data), dan modus (nilai yang sering muncul dari suatu data). Dispersi mengukur penyebaran suatu data. Ada beberapa ukuran umum dispersi yang sering digunakan, yaitu standar deviasi (nilai simpangan baku), varian (nilai kuadrat dari standar deviasi) dan standar error mean (estimasi tentang standar deviasi). Distribusi mengukur distribusi suatu data. Ada beberapa ukuran umum distribusi yang sering digunakan, yaitu: skewness (nilai kemencengan distribusi data), kurtosis (nilai keruncingan data).

\section{Pengelolaan Dengan Model Persamaan Struktural (SEM)}

\section{a. Penyusunan Model Berbasis Teori}

Pengujian model berbasis teori dilakukan dengan menggunakan software AMOS Versi 7.0.

Berikut adalah hasil pengujian model tersebut: 


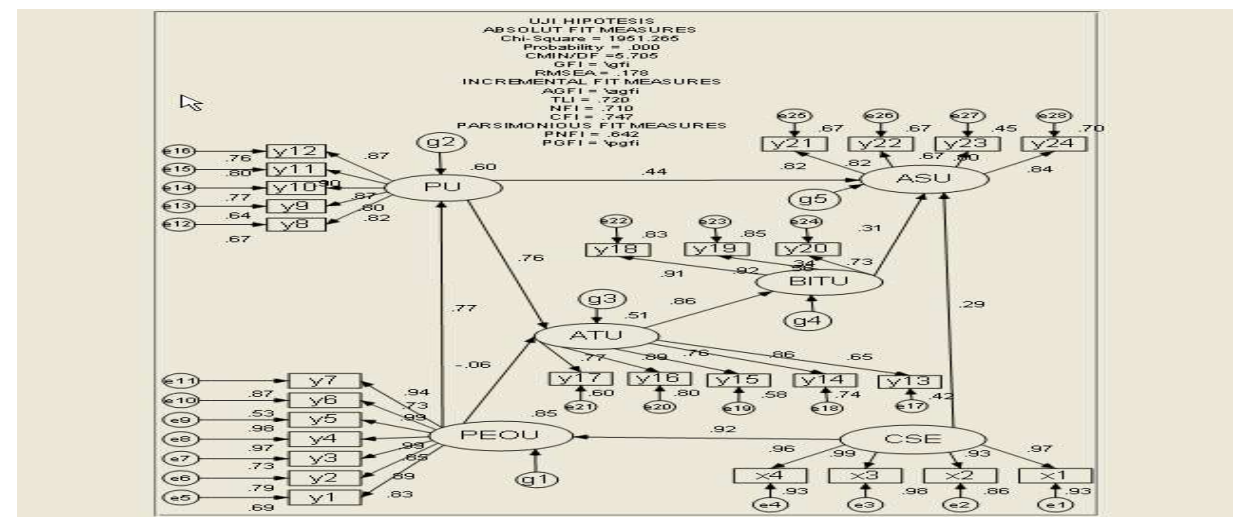

Gambar 2. Model Awal Penelitian Dengan AMOS 7.0

\section{b. Pengujian Validitas}

Pengujian terhadap validitas variabel laten dilakukan dengan melihat nilai signifikansi (Sig) yang diperoleh tiap variabel indikator kemudian dibandingkan dengan nilai $\alpha(0.05)$. Jika Sig $\leq 0.05$ maka Tolak $\mathrm{H}_{0}$, artinya variabel indikator tersebut merupakan konstruktor yang valid bagi variabel laten tertentu (Widodo, 2006b).

\section{1) Variabel Laten Eksogen CSE (Computer Self Efficacy)}

\section{Tabel 2. Uji Variabel CSE}

\begin{tabular}{cccc}
\hline CSE & Estimate & Hasil Hipotesis & Keterangan \\
\hline $\mathrm{x} 1$ & 0.963 & Tolak $\mathrm{H}_{0}$ & Konstruk yang valid \\
x2 & 0.934 & Tolak $\mathrm{H}_{0}$ & Konstruk yang valid \\
x3 & 0.990 & Tolak $\mathrm{H}_{0}$ & Konstruk yang valid \\
x4 & 0.958 & Tolak $\mathrm{H}_{0}$ & Konstruk yang valid \\
\hline
\end{tabular}

Masing-masing variabel indikator $\mathrm{x} 1$ (dapat mengoperasikan komputer), $\mathrm{x} 2$ (dapat menginstal software), x3 (dapat menjalankan software), dan x4 (dapat mengoperasikan aplikasi office) secara signifikan merupakan konstruktor yang valid (tolak $\mathrm{H}_{0}$ ) bagi variabel laten CSE. Terbukti dari nilai yang diperoleh $\mathrm{x} 1, \mathrm{x} 2$, x3, dan $\mathrm{x} 4$ pada uji parameter model pengukuran variabel CSE dengan nilai estimasi $\geq 0.5$. Maka dapat dikatakan bahwa guru dan orang tua Taman Kanak-kanak di Jagakarsa memiliki kemampuan dalam mengoperasikan komputer, menginstal software, menjalankan software dan mengoperasikan aplikasi office).

\section{2) Variabel Laten Endogen}

\section{(1) PEOU (Perceived Ease Of Use)}

\section{Tabel 3. Uji Parameter PEOU}

\begin{tabular}{cccc}
\hline PEOU & Estimate & Hasil Hipotesis & Keterangan \\
\hline y1 & 0.827 & Tolak $\mathrm{H}_{0}$ & Konstruk yang valid \\
y2 & 0.891 & Tolak $\mathrm{H}_{0}$ & Konstruk yang valid \\
y3 & 0.849 & Tolak $\mathrm{H}_{0}$ & Konstruk yang valid \\
y4 & 0.987 & Tolak $\mathrm{H}_{0}$ & Konstruk yang valid \\
y5 & 0.991 & Tolak $\mathrm{H}_{0}$ & Konstruk yang valid \\
y6 & 0.726 & Tolak $\mathrm{H}_{0}$ & Konstruk yang valid \\
y7 & 0.935 & Tolak $\mathrm{H}_{0}$ & Konstruk yang valid \\
\hline
\end{tabular}

Variabel indikator y1 (software belajar membaca interaktif mudah didapatkan), y2 (software belajar membaca interaktif fleksibilitas), y3 (software belajar membaca interaktif mudah dipelajari), y4 (software belajar membaca interaktif mudah dipahami), y5 (software belajar membaca interaktif mudah digunakan), y6 (software belajar membaca interaktif mudah 
untuk anak menjadi trampil), dan y7 (software belajar membaca interaktif mudah untuk dioperasikan) secara signifikan merupakan konstruktor yang valid (tolak $\mathrm{H}_{0}$ ) bagi variabel laten PEOU. Terbukti dari nilai yang diperoleh y1, y2, y3, y4, y5, y6, dan y7 pada uji parameter model pengukuran variabel PEOU dengan nilai estimasi $\geq 0.5$. Maka dapat dikatakan bahwa Software belajar membaca interaktif anak mudah didapatkan, Software belajar membaca interaktif anak fleksibilitas, Software belajar membaca interaktif anak mudah dipelajari, mudah dipahami, mudah digunakan, Software belajar membaca interaktif anak mudah untuk anak menjadi trampil, dan Software belajar membaca interaktif anak mudah untuk dioperasikan.

\section{(2). PU (Perceived Usefulness)}

Tabel 4. Uji Parameter Variabel PU

\begin{tabular}{cccc}
\hline PU & Estimate & Hasil Hipotesis & Keterangan \\
\hline y8 & 0.752 & Tolak $\mathrm{H}_{0}$ & Konstruk yang valid \\
y9 & 0.795 & Tolak $\mathrm{H}_{0}$ & Konstruk yang valid \\
y10 & 0.897 & Tolak $\mathrm{H}_{0}$ & Konstruk yang valid \\
y11 & 0.940 & Tolak $\mathrm{H}_{0}$ & Konstruk yang valid \\
y12 & 0.845 & Tolak $\mathrm{H}_{0}$ & Konstruk yang valid \\
\hline
\end{tabular}

Variabel y8 (penggunaan software belajar membaca interaktif dapat mempercepat pekerjaan), y9 (Software belajar membaca interaktif dapat membantu anak mengenal huruf), y10 (dengan software belajar membaca interaktif dapat memperbaiki efektivitas belajar pada anak), y11 (software belajar membaca interaktif dapat meningkatkan efektivitas belajar pada anak), dan y12 (software belajar membaca interaktif dapat mempermudah pekerjaan dalam mengajar membaca anak-anak) secara signifikan merupakan kontruktor yang valid (tolak $\mathrm{H}_{0}$ ) bagi variabel laten PU. Terbukti dari nilai yang diperoleh y8, y9, y10, y11, dan y12 pada uji parameter model pengukuran variabel PU dengan estimasi $\geq 0.5$. Maka dapat dikatakan bahwa software belajar membaca interaktif dapat membantu mempercepat pekerjaan, membantu anak dalam mengenal huruf, dapat memperbaiki efektivitas belajar pada anak, dapat meningkatkan efektivitas belajar pada anak, dan dapat mempermudah pekerjaan dalam mengajar membaca pada anak).

\section{(3). ATU (Attitude Toward Using)}

Tabel 5. Uji Parameter Variabel ATU

\begin{tabular}{cccc}
\hline ATU & Estimate & Hasil Hipotesis & Keterangan \\
\hline y13 & 0.598 & Tolak $\mathrm{H}_{0}$ & Konstruk yang valid \\
y14 & 0.795 & Tolak $\mathrm{H}_{0}$ & Konstruk yang valid \\
y15 & 0.897 & Tolak $\mathrm{H}_{0}$ & Konstruk yang valid \\
y16 & 0.940 & Tolak $\mathrm{H}_{0}$ & Konstruk yang valid \\
y17 & 0.845 & Tolak $\mathrm{H}_{0}$ & Konstruk yang valid \\
\hline
\end{tabular}

Variabel indikator y13 (menggunakan software belajar membaca interaktif merupakan ide baik), y14 (menggunakan software belajar membaca interaktif anak merupakan sesuatu hal yang positif)), y15 (merasa dapat menerima software belajar membaca interaktif anak), y16 (menggunakan software belajar membaca interaktif merupakan tindakan yang menguntungkan), dan y17 (menggunakan software belajar interaktif anak dapat menambah kreativitas anak) secara signifikan merupakan kontruktor yang valid $\left(\right.$ Tolak $\mathrm{H}_{0}$ ) bagi variabel laten ATU. Nilai yang diperoleh y13, y14, y15, y16, dan y17 pada uji parameter model pengukuran variabel ATU dengan nilai estimasi $\geq 0.5$. Maka dapat dikatakan bahwa menggunakan software belajar membaca interaktif merupakan ide baik, merupakan sesuatu 
hal yang positif, merasa dapat menerima software belajar interaktif, menggunakan software belajar membaca interaktif merupakan tindakan yang menguntungkan, dan dapat menambah kreativitas anak.

\section{(4). BITU (Behavioral Intention To Use)}

Tabel 6. Uji Parameter Variabel BITU

\begin{tabular}{cccc}
\hline BITU & Estimate & Hasil Hipotesis & Keterangan \\
\hline y18 & 0.823 & Tolak $\mathrm{H}_{0}$ & Konstruk yang valid \\
y19 & 1.019 & Tolak $\mathrm{H}_{0}$ & Konstruk yang valid \\
y20 & 0.590 & Tolak $\mathrm{H}_{0}$ & Konstruk yang valid \\
\hline
\end{tabular}

Variabel indikator y18 (niat untuk menggunakan software belajar interaktif), y19 (niat untuk meningkatkan penggunaan), dan y20 (menggunakan software interaktif belajar interaktif merupakan tindakan yang menguntungkan) secara signifikan merupakan konstruktor yang valid (Tolak $\mathrm{H}_{0}$ ) bagi variabel laten BITU. Terbukti dari nilai y18, y19 dan y20 yang diperoleh pada uji parameter model pengukuran variabel BITU dengan nilai estimasi $\geq 0.5$.

(5). ASU (Actual System Usage)

Tabel 7. Uji Parameter Variabel ASU

\begin{tabular}{cccc}
\hline ASU & Estimate & Hasil Hipotesis & Keterangan \\
\hline y21 & 0.790 & Tolak $\mathrm{H}_{0}$ & Konstruk yang valid \\
y22 & 0.840 & Tolak $\mathrm{H}_{0}$ & Konstruk yang valid \\
y23 & 0.717 & Tolak $\mathrm{H}_{0}$ & Konstruk yang valid \\
y24 & 0.832 & Tolak $\mathrm{H}_{0}$ & Konstruk yang valid \\
\hline
\end{tabular}

Berdasarkan Tabel 7., dapat diketahui bahwa masing-masing variabel indikator y21 (penggunaan software belajar membaca interaktif nyata), y22 (frekuensi penggunaan software belajar membaca anak sering), y23 (durasi penggunaan maximun 60 menit dalam sehari), y24 (merasa puas menggunakan software belajar membaca interaktif anak) secara signifikan merupakan konstruktor yang valid $\left(\right.$ Tolak $\mathrm{H}_{0}$ ) bagi variabel laten ASU (Actual System Usage). Nilai yang diperoleh y21, y22, y23, dan y24 pada uji parameter model pengukuran variabel ASU dengan nilai estimasi $\geq 0.5$. Maka dapat dikatakan bahwa orang tua dan guru menggunakan software belajar membaca interaktif secara nyata, frekuensi penggunaan sering, durasi penggunaan maximun 60 menit dalam sehari, dan merasa puas menggunakan software belajar membaca interaktif.

\section{c. Pengujian Reliabilitas}

Tabel 8. Uji Reliabilitas Gabungan

\begin{tabular}{ccc}
\hline Variabel Laten & Contruct Reliability & Variance Extracted \\
\hline CSE & 0.981 & 0.929 \\
PEOU & 0.964 & 0.794 \\
PU & 0.927 & 0.720 \\
ATU & 0.891 & 0.626 \\
BITU & 0.863 & 0.688 \\
ASU & 0.873 & 0.634 \\
\hline
\end{tabular}

Pada tabel 8 terlihat bahwa CSE, PEOU, PU, ATU, BITU, dan ASU memiliki nilai Construct Reliability di atas 0.70. Nilai Variance Extracted yang dimiliki CSE, PEOU, PU, ATU, BITU, dan ASU di atas $\geq 0.50$. Dengan demikian dapat dikatakan bahwa masingmasing variabel memiliki reliabilitas yang baik. 
Dari hasil uji validitas dan reliabilitas, model penelitian masih tetap sama dengan model berdasarkan teori dikarenakan pada setiap variabel tidak ada indikator yang bernilai tidak valid, maka model penelitan dapat dilihat pada gambar 3 .

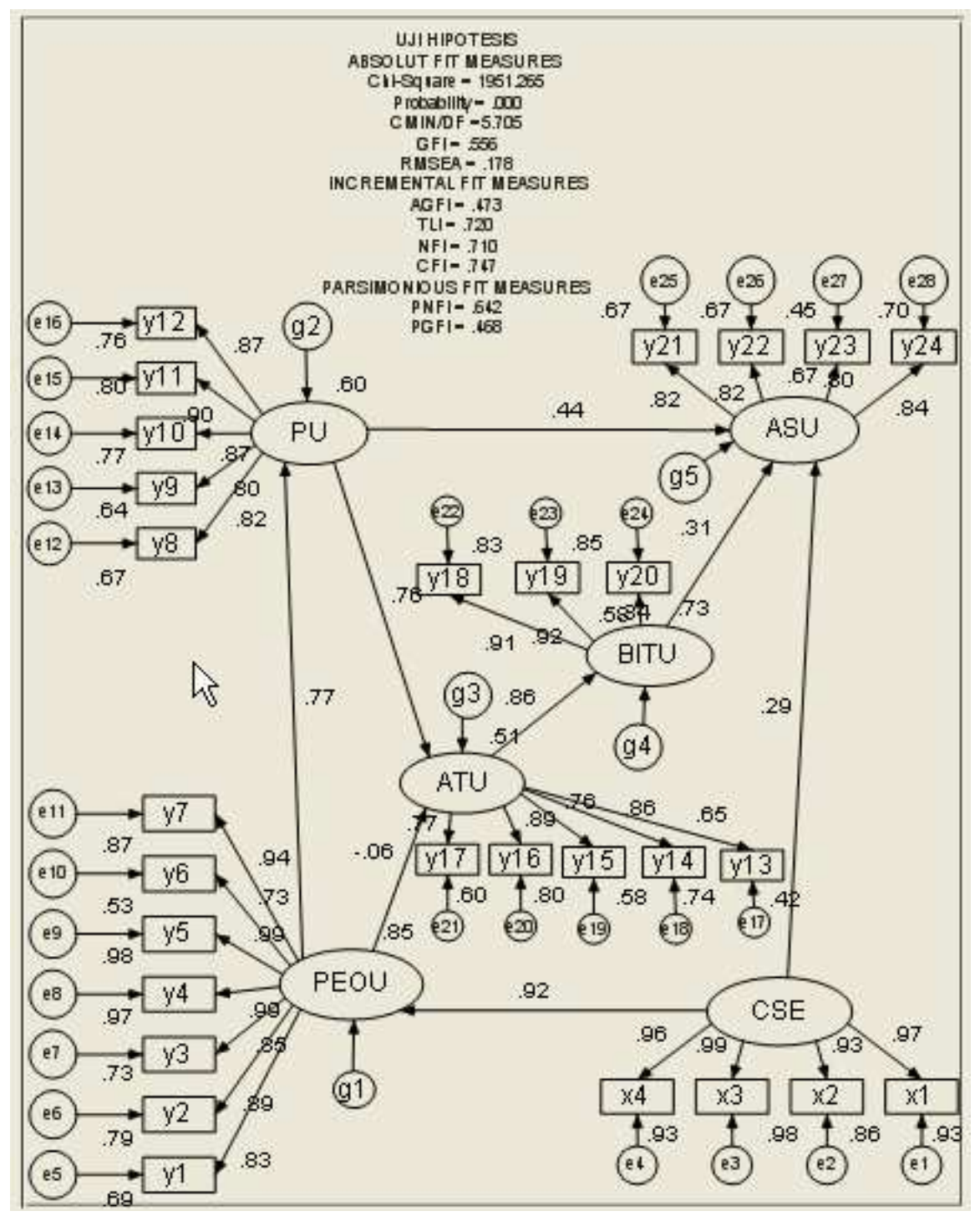

Gambar 3. Model Setelah Uji Confirmatory 


\section{Analisis Statistik Inferensial}

\section{Uji Asumsi Model}

1. Ukuran Sampel

Ukuran sampel yang harus dipenuhi dalam pemodelan SEM, minimum berjumlah 100 . Penelitian ini menggunakan 150 sampel, oleh karena itu jumlah sampel tersebut telah memenuhi persyaratan ukuran sampel.

2. Uji Normalitas

Hasil Uji Normalitas disajikan pada Tabel Assesment of Normality yang terdapat pada lampiran 5, dapat dilihat bahwa nilai yang berada pada kolom c.r. semuanya berada dalam kisaran nilai yang direkomendasikan yaitu antara -2.58 sampai 2.58 . Oleh karena itu dapat dikatakan bahwa data terdistribusi secara normal. Data memenuhi syarat untuk dilakukan analisis selanjutnya.

\section{Outliers}

Pada tabel Mahalanobis Distance yang terdapat pada lampiran 6, dapat dilihat pada Mahalanobis $d$-squared bahwa ada nilai yang diuji yang lebih besar dari $\chi^{2}$ tabel, artinya terdapat outlier.

\section{Multikolinearitas dan Singularitas}

Pada Tabel Sample Covariances yang terdapat pada lampiran 7, dapat dilihat pada Determinant of sample covariance matrix bernilai .000 yang berarti jauh dari nilai nol, sehingga tidak terdapat masalah multikolinearitas dan singularitas pada data yang dianalisis, sehingga data dinyatakan valid.

\section{d. Uji Kesesuaian Model}

Hipotesis yang menjelaskan kondisi data empiris dengan model adalah:

$\mathrm{H}_{0} \quad$ : Data empirik identik dengan teori atau model (Hipotesis diterima apabila $\mathrm{P} \geq$ $0.05)$.

$\mathrm{H}_{1} \quad$ : Data empirik berbeda dengan teori atau model (Hipotesis ditolak apabila $\mathrm{P}<0.05$ ).

Tabel 9. Uji Perbandingan Kesesuaian Model

\begin{tabular}{|c|c|c|c|}
\hline Ukuran Kesesuaian & $\begin{array}{c}\text { Batas nilai } \\
\text { kritis }\end{array}$ & $\begin{array}{l}\text { Hasil } \\
\text { model } \\
\text { ini }\end{array}$ & Ket \\
\hline \multicolumn{4}{|c|}{ 1. Absolut Fit Measures } \\
\hline (1) Chi-Squares $X^{2}(\mathrm{CMIN})$ & $\begin{array}{l}\text { Kecill, } \leq x^{2} \alpha \\
; d f\end{array}$ & 2447.620 & Tidak Baik \\
\hline $\begin{array}{l}\text { (2) Probability } \\
\text { (3) Chi-Squares X² Relatif } \\
\text { (CMIN/DF) }\end{array}$ & $\begin{array}{l}\geq 0.05 \\
\leq 2.0\end{array}$ & $\begin{array}{r}.000 \\
7.157\end{array}$ & $\begin{array}{l}\text { Tidak Baik } \\
\text { Tidak Baik }\end{array}$ \\
\hline (4) GFI & $\geq 0.90$ & 0.478 & Tidak Baik \\
\hline (5) RMSEA & $\leq 0.08$ & 0.227 & Tidak Baik \\
\hline \multicolumn{4}{|c|}{ 2. Incremental Fit Measures } \\
\hline (1) AGFI & $\geq 0.90$ & 0.380 & Tidak Baik \\
\hline (2) TLI & $\geq 0.95$ & 0.582 & Tidak Baik \\
\hline (3) NFI & $\geq 0.90$ & 0.588 & Tidak Baik \\
\hline (4) $\mathrm{CFI}$ & $\geq 0.95$ & 0.622 & Tidak Baik \\
\hline \multicolumn{4}{|c|}{ 3. Parsimonious Fit Measaures } \\
\hline (1) PNFI & $\geq 0.60$ & 0.532 & Tidak Baik \\
\hline (2) PGFI & $\geq 0.60$ & 0.402 & Tidak Baik \\
\hline
\end{tabular}

(Sumber : Olah data AMOS 7.0 sesuai batas nilai kritis

Widodo, 2006a) 
Model Jalur (Path Analysis)

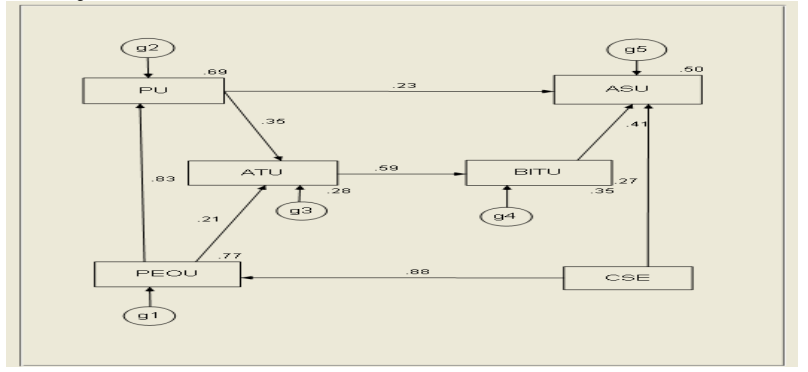

Gambar 4. Model Penelitian Dengan Analisis Jalur

Uji Signifikasi

Tabel 10. Uji Signifikasi Model Jalur

\begin{tabular}{lcc}
\hline \multicolumn{1}{c}{ Variabel Indikator } & Estimate & Keterangan \\
\hline $\mathrm{CSE} \rightarrow$ PEOU & 1.080 & Hubungan signifikan \\
$\mathrm{PEOU} \rightarrow$ PU & 0.354 & Hubungan signifikan \\
$\mathrm{PEOU} \rightarrow$ ATU & 0.055 & Hubungan signifikan \\
$\mathrm{PU} \rightarrow$ ATU & 0.218 & Hubungan signifikan \\
$\mathrm{ATU} \rightarrow$ BITU & 0.664 & Hubungan signifikan \\
$\mathrm{PU} \rightarrow$ ASU & 0.159 & Hubungan signifikan \\
$\mathrm{BITU} \rightarrow$ ASU & 0.412 & Hubungan signifikan \\
$\mathrm{CSE} \rightarrow$ ASU & 0.097 & Hubungan signifikan \\
\hline
\end{tabular}

\section{Simpulan dan Saran}

\section{Simpulan}

1. Faktor-faktor yang mempengaruhi tingkat penerimaan Software Belajar Membaca Interaktif pada anak usia dini di Taman Kanak-kanak pada penelitian kajian penggunaan Software Belajar Membaca Interaktif meliputi Computer Self Efficacy (kemampuan diri pada komputer), Perceived Ease of Use (persepsi kemudahan penggunaan), Perceived Usefulness (persepsi Kemanfaatan), Attitude Toward Using (sikap untuk menggunakan), Behavioral Toward Using (sikap untuk menggunakan), dan Actual System Usage (penggunaan nyata sistem).

2. Hubungan kausal antara faktor-faktor yang mempengaruhi penerimaan software belajar membaca interaktif di Taman Kanak-kanak adalah sebagai berikut:

a. Variabel CSE (kemampuan komputer) secara signifikan berpengaruh terhadap variabel PEOU (kemudahan penggunaan).

b. Variabel PEOU (kemudahan penggunaan) software belajar membaca interaktif secara signifikan berpengaruh terhadap variabel PU (kemanfaatan).

c. Variabel PEOU (kemudahan penggunaan) software belajar membaca interaktif secara signifikan berpengaruh terhadap variabel ATU (sikap untuk menggunakan) software belajar interaktif

d. Variabel PU (kemanfaatan) software belajar membaca interaktif secara signifikan berpengaruh terhadap variabel ATU (sikap untuk menggunakan) software belajar membaca interaktif.

e. Variabel ATU (sikap untuk menggunakan) software belajar interaktif secara signifikan berpengaruh terhadap variabel BITU (perilaku niat untuk menggunakan).

f. Variabel PU (kemanfaatan) software belajar membaca interaktif secara signifikan berpengaruh terhadap variabel ASU (penggunaan nyata sistem).

g. Variabel CSE (kemampuan komputer) secara signifikan berpengaruh terhadap variabel ASU (penggunaan nyata sistem). 
h. Variabel BITU (perilaku niat untuk menggunakan) software belajar membaca interaktif secara signifikan berpengaruh terhadap variabel ASU (penggunaan nyata sistem).

3. Squared Multiple Correlations $\left(\mathrm{R}^{2}\right)$ pada tingkat penerimaan sofware Belajar Membaca Interaktif pada anak usia dini Taman Kanak-kanak di wilayah kecamatan Jagakarsa adalah sebagai berikut:

a. Keragaman PEOU yang digunakan adalah sebesar 76,8\% (PEOU : 0.768)

b. Keragaman PU yang digunakan adalah sebesar $68,9 \%$ (PU : 0.689)

c. Keragaman ATU yang digunakan adalah sebesar $28,3 \%$ (ATU : 0.283 )

d. Keragaman BITU yang digunakan adalah sebesar 35,2\% (BITU : 0.352)

e. Keragaman ASU yang digunakan adalah sebesar 49,9\% (ASU : 0.499)

4. Dari hasil kesesuaian model diperoleh penjelasan bahwa data lapangan tidak mendukung adanya model yang fit (sesuai) dengan data aslinya (populasinya), maka kesimpulan yang dinyatakan pada butir 1 (satu) sampai 3 (tiga) hanya berlaku untuk sampel penelitian yaitu pengguna software belajar membaca interaktif di Taman Kanakkanak wilayah Kecamatan Jagakarsa.

\section{Saran}

1. Aspek Manajerial; berbubungan dengan media pembelajaran yaitu Belajar membaca dengan media software belajar membaca interaktif harus lebih ditingkatkan dalam hal penggunaan (praktek). Di Taman Kanak-kanak diharapkan menyedikan laboratorium komputer sehingga anak didik akan lebih nyaman dalam menggunakan komputer dan 1 (satu) komputer disediakan hanya untu satu orang anak. Adakan pelatihan pada guru-guru yang mengajar yang menggunakan media software belajar membaca intraktif agar guru lebih menguasai materi yang akan disampaikan. Adakan sosialisasi kepada orang tua untuk menggunakan software belajar membaca interaktif dirumah.

2. $\quad$ Aspek Sistem; sekolah Taman Kanak-kanak harus menyediakan infrastruktur yang layak untuk dapat digunakannya software interaktif belajar membaca dan diharapkan juga agar sekolah Taman Kanak-kanak selalu mengugrade Software Belajar Membaca Interaktif, agar anak-anak tidak merasa bosan dengan menu-menu yang ada sebelumnya pada software belajar membaca interaktif.

3. Aspek Penelitian Lanjutan; hasil penelitian ini dapat dikembangkan dalam penelitian lanjutan dengan cakupan yang lebih luas, misalkan dilakukan penelitian untuk beberapa Taman Kanak-kanak di Wilayah Jakarta Selatan dan penelitiannya dapat dikaji secara periodik. Hasil penelitian ini dapat dikembangkan dalam penelitian lanjutan dengan model atau pendekatan lain yang masih relevan dengan kasus ini.

\section{Daftar Pustaka}

Davis F.D., (1989). Perceived Usefulness, Perceived Ease of Use Of Information, Management Information System Quarterly.

Hair, J.F. (1998). Multivariat Data Analysis. New Jersey: Prentice Hall

Iqbaria, M. (1994). An Examination of the Factors Contributing Acceptance Journal of Information System, Elsiever Ecience, USA.

Indriantoro Nur. (2000). Pengaruh Computer Anxiety Terhadap Keahlian Dosen Dalam Penggunaan Komputer. Jurnal Akuntansi dan Auditing (JAAI), Vol.3 No.1, FE UII. Yogyakarta.

Widodo, P. (2006). Theory of Reasoned Action (TRA), Jakarta.

Widodo, P. (2006). Theory of Planned Behavior (TPB), Jakarta

Widodo, P. (2006). Theory Acceptance Model (TAM), Jakarta

eMedio (Studio Media Edukasi). Diakses pada: http://softwarebelajar.blogspot.com. Email:emedio@gmail.com 